\title{
Teaching reforming practice of Engineering Chemistry course in Civil Engineering major at Guangdong University of Technology
}

\author{
Xianghua Yang ${ }^{1,2,}$, Xiaoling Cheng ${ }^{1,2}$, Ming Sun ${ }^{1,2}$, Hongsheng Luo ${ }^{1}$ and Jun \\ $\mathrm{He}^{1,2, \mathrm{~b}}$ \\ ${ }^{1}$ School of Chemical Engineering and Light Industry, Guangdong University of Technology, Guangzhou \\ 510006 China
}

${ }^{2}$ Key Laboratory of Clean Chemistry Technology of Guangdong Regular Higher Education Institutions, Guangzhou 510006 China

a yangxianghua@gdut.edu.cn, b junhe@gdut.edu.cn

Keywords: Engineering Chemistry, Civil Engineering major, Teaching reform, GDUT

Abstract. The course of Engineering Chemistry is a specialized course developed in recent years for students of engineering majors other than chemistry or chemical engineering, teaching reforming practice of this course with the civil engineering major as an example at Guangdong University of Technology was described herein.

\section{Introduction}

The course of Engineering Chemistry is a specialized course developed in recent years for students of engineering majors other than chemistry or chemical engineering, such as mechanical engineering, automation and civil engineering majors. Since Guangdong University of Technology (GDUT) is the biggest engineering-specialized university in Guangdong province with more than 50,000 full-time students, nearly 10,000 undergraduate-students have to attend this course during their study here. As the only chemistry-related school in GDUT, the school of chemical engineering and light industry was assigned to provide this course to the whole university. In order to carry out this course effectively and efficiently, teaching reforming practice is imminent.

With chemical principles as the warp, and the chemical application of chemistry in many fields including material, information, energy, environment and life as the weft, the basics of the four major chemistry courses are covered in this course [1] (Fig 1).

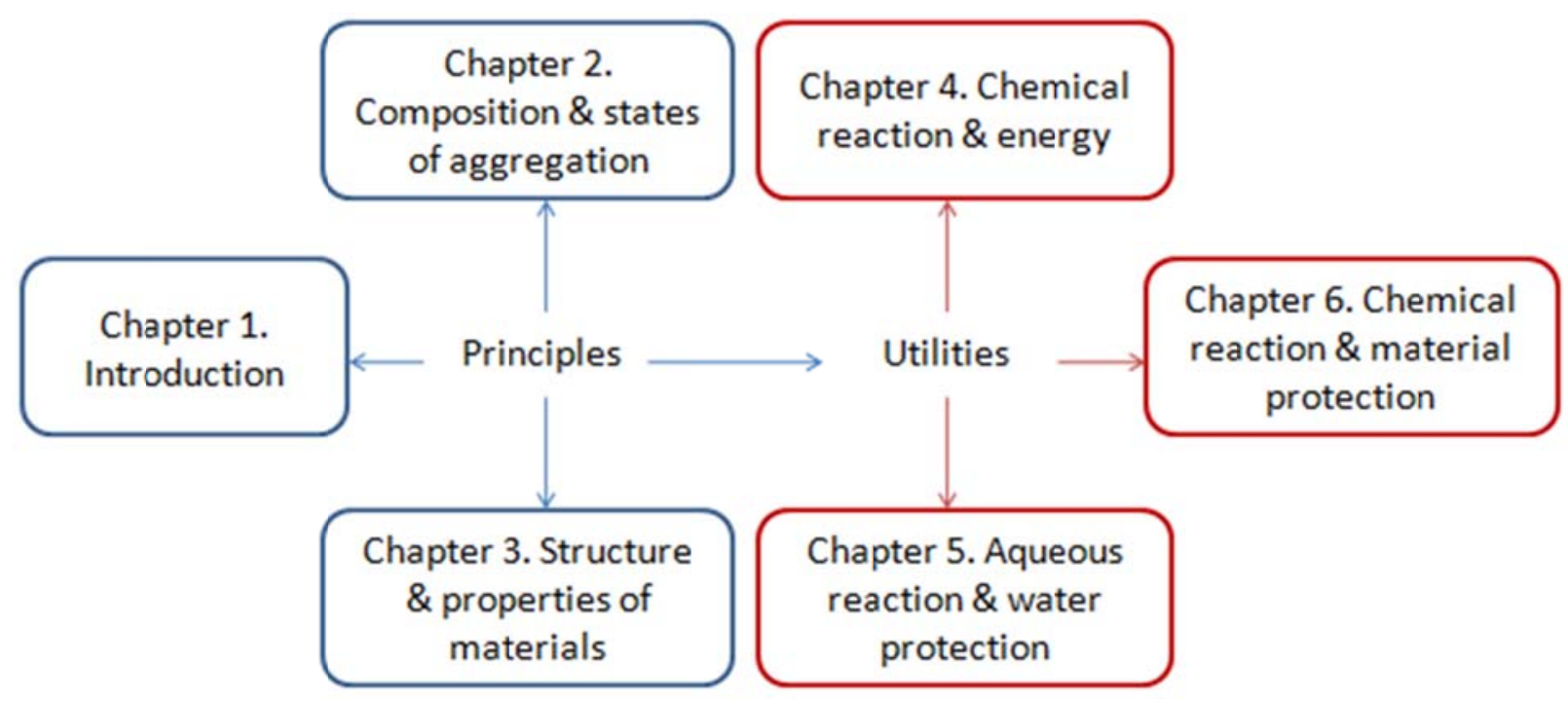

Fig. 1 Contents design of the Engineering Chemistry course. 
However, the basis of chemistry knowledge of these students is rather weak, and only 32 teaching-hours was arranged for this course. These facts make it of vital importance for the teacher to select appropriate content and prepare proper materials. In this paper, with students major in civil engineering as an example [2], we proposed an engineering chemistry teaching method which not only being closely related to the major, but also can effectively expand the students' knowledge. During the teaching practice, application of civil engineering- related knowledge were focused on, such as the selection, utilization, corrosion and protection of building materials, knowledge of new materials, protection of environment, and so on, as described below:

\section{Chemical principles for the selection of building materials}

Building materials usually include structural materials such as cement, sand, masonry, construction steel, and functional materials like waterproof materials, decorative materials, thermal insulation and sound absorption material. Among them, the correct selection of structural materials is critical, which determines the stability of the building structure and its durable years. For example, a reinforced concrete structure majorly involves cement, rebar and sand. Therefore, the gelling properties of the cement, the size and corrosion resistance of the reinforcing bar, and the fineness and content of chlorine ion of the sand all together determined the nature of the reinforced concrete. And the selection of these materials, on the one hand, based on mechanics; on the other hand, it also involves a lot of chemical principles. As is known to all, reinforcing bar gets easily rusted in the air due to the action of water and oxygen. While in the concrete, the strong alkaline environment generated by hydrating of the cement can oxidize the steel bar surface, forming a dense layer of ferric oxide protective film (or passivation film). Together with the surrounding concrete, water and oxygen are strictly isolated and the reinforcing bar was therefore protected from rusting.

However, if sea sand, which contains a large number of small and active chloride ions, was applied [3], the chloride ion in the concrete would undergo gradient concentration diffusion and penetrate through the surficial passivation film on the reinforcing bar. When the internal critical chloride ion concentration for the corrosion of the steel is reached, it will generate micro galvanic cell and pitting corrosion occurred on the steel surface. At the same time, due to the hygroscopic property of salts, sea sand-containing buildings got easily damped, increased amount of moisture will accelerate the corrosion speed of the rebar, reduce its effective sectional area, decrease the bonding force between the rebar and the concrete, resulting in a reduced structural bearing capacity and serious declined durability (Fig. 2). Thus, it's very necessary for the civil engineering students to understand the chemical principles of materials. These examples can be discussed combining with the contents of the sixth chapter "chemical reaction and material protection".

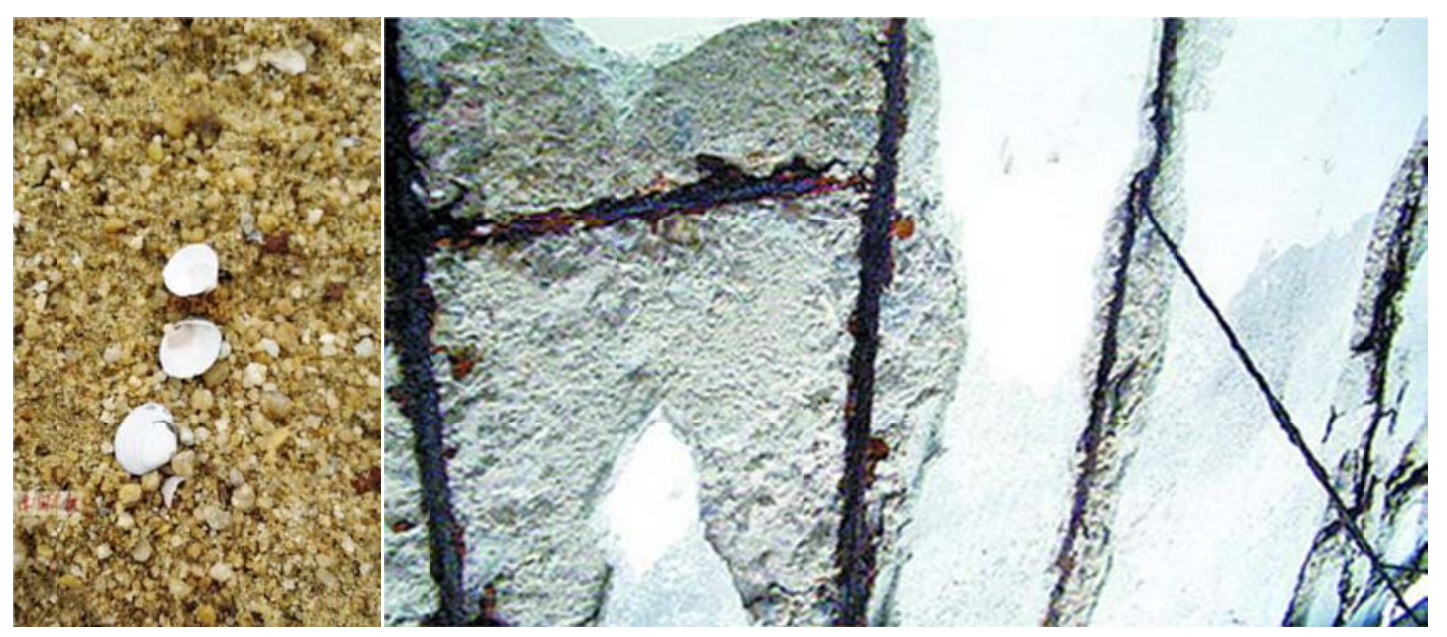

Fig. 2 Sea sand (left) and corrosion of rebar in sea sand-containing concrete (right) [4]. 


\section{Civil engineering-related knowledge of new materials}

New material means materials which were developed recently and exhibit bietter performance than traditional materials. The new material industry is one of the strategic emerging industries in the Twelfth Five-Year Plan of the State Council. New materials which are closely related to civil engineering include: a) high performance composite materials such as high temperature alloy, corrosion resistant alloy, corrosion resistant steel, aluminum alloy, magnesium alloy, titanium alloy, etc.; b) new pattern inorganic non-metal materials such as piezoelectric ceramics, silicon carbide ceramics and special glass; c) other frontier high performance composite materials like nano materials, graphene and intelligent materials. Knowledge of these materials can be introduced in the second, third and sixth chapters. Among them, the discoverers of carbon cluster $\mathrm{C}_{60}-$ the British chemist Harold W. Kroto and the American chemists Richard E. Smalley and Robert F. Curl won the 1996 Nobel Prize in chemistry. The British scientists Andre Geim and Kostya S. Novoselov won the 2010 Nobel Prize in physics due to their excellent research in graphene material (Fig. 3) [5]. Teaching of these new materials-related Nobel Prize examples in class is expected to further stimulate students' interest in learning and their innovation spirit.
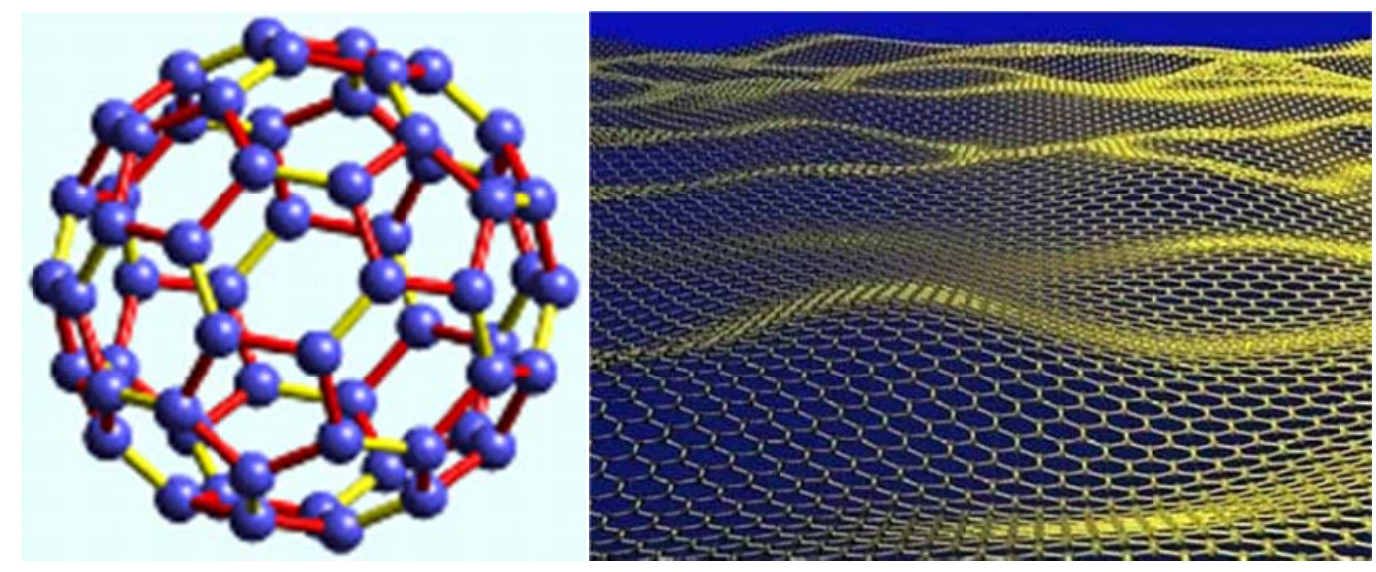

Fig. 3 Carbon clusters $\mathrm{C}_{60}$ (left) and graphene (right).

\section{Civil engineering-related knowledge of environment protection and energy}

With the acceleration of the global economic development and urbanization, the environmental pollution is becoming increasingly serious. Construction industry, as a pillar industry of our country, has promoted the rapid development of building materials industry. In the meanwhile, the building materials industry is the largest consumption of natural resources and energy resources, which not only damaged the largest green land area, but also produced a large number of solid waste and gaseous pollutants. In order to achieve sustainable development, building materials must take the road of green, which is undoubtedly a challenge to the new chemical building materials. According to the plans of our country, the development of chemical building materials will be highlighted on new waterproof materials such as plastic composite pipe, plastic doors and windows, take energy saving, environmental protection and functional materials as the direction. At the same time, in the premise of not affecting the quality of construction, technologies such as empty walls and micro bubbles can be used to reduce the cost and to save raw materials [6]. In addition, when teaching the fourth chapter, we can mention the energy shortage we are currently facing, focus on the use of renewable resources such as solar energy, wind energy, etc.

\section{Summary}

Applying these skills, we are expected to stimulate the students' interest, improve the teaching efficiency, and enhance their ability of combining theory with practice. 


\section{Acknowledgements}

This work was financially supported by GDUT and the Education Bureau of Guangdong province as a '2015 Quality Project' constructing project.

\section{References}

[1] Lingen Chen: Engineering Chemistry (Second Edition) (Beijing: Higher Education Press, 2005).

[2] Yixian Zhang: The Construction of Higher Education Vol. 1 (2000), p. 38-39.

[3] Faguang Leng, Wei Ding, Yongxiang Zhou, Yuenian Zhou, Xiankun Ji and Jing Wang: Engineering Quality Vol. 1 (2011), p. 12-16.

[4] Information on http://www.xmnn.cn/dzbk/xmrb/20130317/201303/t20130317_3122688.htm.

[5] Xiaodan Wang, Peng Lin, Minjie Luan, Yulan Ren and Yufeng Jiao: Liren: Teacher Vol. 19 (2014), p. 224.

[6] Yangai Zhang: Construction Technology and Design Vol. 22 (2014), p. 455. 